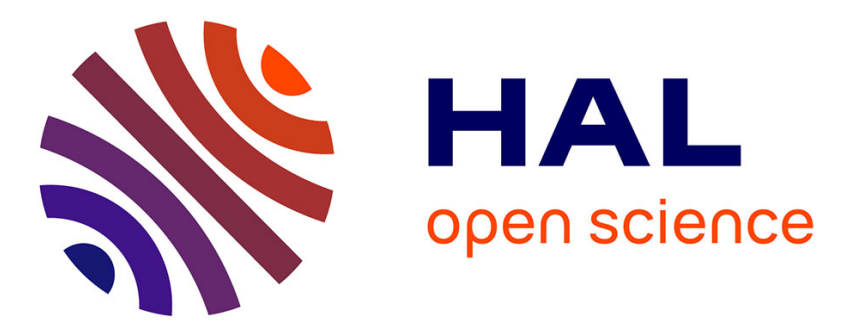

\title{
Injury-induced mineralocorticoid receptor expression involves differential promoter usage: a novel role for the rat $\operatorname{MR} \beta$ variant
}

Peng Kang, Justyna Rogalska, Catherine A. Walker, Matthew Burke, Jonathan R. Seckl, Malcolm R. Macleod, Maggie Lai

\section{To cite this version:}

Peng Kang, Justyna Rogalska, Catherine A. Walker, Matthew Burke, Jonathan R. Seckl, et al.. Injury-induced mineralocorticoid receptor expression involves differential promoter usage: a novel role for the rat $\mathrm{MR} \beta$ variant. Molecular and Cellular Endocrinology, 2009, 305 (1-2), pp.56. 10.1016/j.mce.2009.02.008 . hal-00499117

\section{HAL Id: hal-00499117 https://hal.science/hal-00499117}

Submitted on 9 Jul 2010

HAL is a multi-disciplinary open access archive for the deposit and dissemination of scientific research documents, whether they are published or not. The documents may come from teaching and research institutions in France or abroad, or from public or private research centers.
L'archive ouverte pluridisciplinaire HAL, est destinée au dépôt et à la diffusion de documents scientifiques de niveau recherche, publiés ou non, émanant des établissements d'enseignement et de recherche français ou étrangers, des laboratoires publics ou privés. 


\section{Accepted Manuscript}

Title: Injury-induced mineralocorticoid receptor expression involves differential promoter usage: a novel role for the rat MR $\beta$ variant

Authors: Peng Kang, Justyna Rogalska, Catherine A. Walker, Matthew Burke, Jonathan R. Seckl, Malcolm R. Macleod,

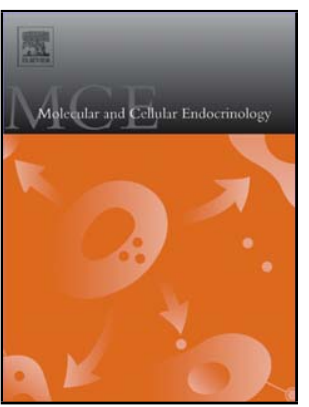

Maggie Lai

PII:

S0303-7207(09)00129-4

DOI: doi:10.1016/j.mce.2009.02.008

Reference: MCE 7143

To appear in: $\quad$ Molecular and Cellular Endocrinology

Received date: $\quad 18-12-2008$

Revised date: $\quad 3-2-2009$

Accepted date: $\quad$ 12-2-2009

Please cite this article as: Kang, P., Rogalska, J., Walker, C.A., Burke, M., Seckl, J.R., Macleod, M.R., Lai, M., Injury-induced mineralocorticoid receptor expression involves differential promoter usage: a novel role for the rat MR $\beta$ variant, Molecular and Cellular Endocrinology (2008), doi:10.1016/j.mce.2009.02.008

This is a PDF file of an unedited manuscript that has been accepted for publication. As a service to our customers we are providing this early version of the manuscript. The manuscript will undergo copyediting, typesetting, and review of the resulting proof before it is published in its final form. Please note that during the production process errors may be discovered which could affect the content, and all legal disclaimers that apply to the journal pertain. 
Injury-induced mineralocorticoid receptor expression involves differential promoter usage: a novel role for the rat MR $\beta$ variant

Peng Kang ${ }^{a}$, Justyna Rogalska ${ }^{c}$, Catherine A. Walker ${ }^{a}$, Matthew Burke ${ }^{a}$, Jonathan R. Seckl ${ }^{a}$, Malcolm R. Macleod ${ }^{b}$, Maggie Lai ${ }^{a *}$

${ }^{a}$ Endocrinology Unit, Centre for Cardiovascular Science, University of Edinburgh, Scotland, UK ${ }^{b}$ Department of Clinical Neuroscience, Centre for Clinical Brain Sciences, University of Edinburgh, Scotland, UK

'Department of Animal Physiology, Institute of General and Molecular Biology, N. Copernicus University, Torun, Poland

*Corresponding author at: Endocrinology Unit, Centre for Cardiovascular Science, University of Edinburgh, Scotland, UK

Tel: +441312426764

Fax: +44 1312426779

Email: m.lai@ed.ac.uk 


\begin{abstract}
Keywords: Mineralocorticoid receptor, transcript, variant, oxygen-glucose deprivation, hypothermia

Neuronal injury results in increased mineralocorticoid receptor (MR) expression and is associated with increased neuronal survival, suggesting that enhancing MR signalling may have therapeutic implications. MR has a complex gene structure with at least three untranslated exons $(\alpha, \beta, \gamma)$ each with unique promoters and a common coding region. We examined whether distinct cellular stressors differentially regulate exon-specific MR transcripts. MR $\beta$ transcript was specifically upregulated in rat primary cortical cultures undergoing hypothermic oxygen-glucose deprivation $(\mathrm{OGD} / \mathrm{H})$ through activation of its own promoter. This effect was mediated in part by ERK signalling as blockade with PD98059 inhibited $\mathrm{OGD} / \mathrm{H}$-induced MR $\beta$ promoter activity. A specific increase in MR $\beta$ transcript expression was also found in vivo in hypothermic anoxic neonatal rat hippocampus. These results demonstrate a novel key role for the MR $\beta$ transcript in response to injury and suggest that some of the known neuroprotective effects of hypothermia may be mediated through increased MR expression.
\end{abstract}




\section{Introduction}

Glucocorticoid hormones exert multiple effects within the central nervous system amongst which they are potent regulators of neuronal survival. Their actions are mediated by two closely related intracellular receptors: the glucocorticoid receptor $(\mathrm{GR})$ and the mineralocorticoid receptor (MR) which once activated function as transcriptional regulators of target genes (Evans and Arriza, 1989). Under normal conditions high affinity MRs are substantially occupied by physiological levels of glucocorticoids; in contrast the lower affinity GRs only become activated when glucocorticoid levels rise either during the circadian peak or in response to stress (de Kloet et al., 1998). MR signalling is therefore predominantly regulated by receptor abundance whereas GR signalling is more dependent on hormone concentrations. This has important implications and may explain why MR and GR can have opposite actions in neuronal viability where predominant MR activation appears to have a survival effect for instance in dentate gyrus neurons (Woolley et al., 1991) while GR overactivation increases vulnerability to for instance excitotoxicity (Reagan and McEwen, 1997; Sapolsky, 2000).

We have previously shown a rapid induction of MR (mRNA and protein) in vitro in rat primary hippocampal and cortical neuronal cultures following sub-lethal cell stress, and in vivo in rat hippocampus following hypothermic transient global cerebral ischemia (Macleod et al., 2003). In each case pharmacological antagonism with spironolactone increased neuronal death suggesting that MR induction is an endogenous neuroprotective mechanism and may mediate some of the effects of hypothermia. Indeed, in vitro overexpression of human MR (hMR) protects PC12 cells from oxygen-glucose deprivation (OGD) (Lai et al., 2005). Crucially hippocampal neurons in transgenic mice overexpressing MR in forebrain (MR-Tg) have reduced neuronal loss following transient global cerebral ischemia (Lai et al., 2007). Furthermore hippocampal MR is increased in post-mortem samples from patients who had a brief cardiac arrest, and presumed cerebral hypoxia, some weeks prior to death (Lai et al., in press), implying that MR is also increased in human brain following neuronal stress. Taken together these findings suggest that increasing neuronal MR expression might have important therapeutic uses for example in patients at high risk of cerebral ischemic insult.

The regulation of MR gene expression is complex and any clinical exploitation of the neuroprotective effects of increased MR will require an understanding of its regulation following cell stress. The rat MR gene gives rise through alternate splicing to three distinct MR mRNA transcripts $(\mathrm{MR} \alpha, \beta, \gamma)$ which differ in their 5'-untranslated region (Kwak et al., 1993) but encode the same mature protein. Each corresponding 5 ' flanking region acts as a functional promoter allowing independent regulation of each mRNA isoform. Similarly, the human MR gene gives rise to two MR mRNA species controlled by two promoters P1 and P2 (Zennaro et al., 1996) which correspond to rat $M R \alpha$ and $M R \beta$ respectively. These alternate promoters appear to determine tissue- and development-specific expression of the MR gene (Vazquez et al., 1998) and suggest separate mechanisms for upregulation of $\mathrm{MR}$ in response to different stimuli. Indeed, endogenous glucocorticoids appear to regulate the different MR transcripts but other regulators have yet to be identified.

Here, we have investigated the mechanism(s) of cell stress-induced MR upregulation at the molecular and cellular level. We examined the effects of oxygen/glucose deprivation (OGD) and/or hypothermia on MR mRNA variant expression in rat primary neuronal cultures. To study the regulation of these different promoters in response to different cell stressors, we used the luciferase reporter system in rat PC12 cells, and to establish if in vitro findings were of biological relevance in vivo we have also analysed the MR mRNA variant involved in mediating the MR response to anoxia and/or hypothermia in hippocampal neurons of the neonatal rat brain.

\section{Materials and Methods}

All animals were maintained in accordance with the guidelines of the UK Home Office Animals (Scientific Procedures) Act and the Polish Local Committee on the Use and Care of Laboratory Animals.

\subsection{Primary cortical culture}


Primary neuronal cultures were prepared from cerebral cortices of E18 Wistar rat fetuses as described previously (Macleod et al., 2003). Briefly, dissected cortices were dissociated in Hanks balanced salt solution (HBSS) containing trypsin $(1800 \mathrm{U} / \mathrm{ml})$ and DNAse I $(200 \mathrm{U} / \mathrm{ml})$ for 10 minutes at $37^{\circ} \mathrm{C}$. Cells were plated onto poly-D-lysine coated 6 -well multiwell plates (BD Biosciences, Oxford, UK) at a density of $2 \times 10^{5}$ cells $/ \mathrm{cm}^{2}$ in NeurobasalTM medium (Invitrogen, Paisley, UK) supplemented with B27 (Invitrogen) and $0.5 \mathrm{mM}$ L-glutamine (Invitrogen). Cells were grown under humidified conditions of $95 \%$ air $/ 5 \% \mathrm{CO}_{2}$ at $37{ }^{\circ} \mathrm{C}$ with medium changed after 7 days in vitro (d.i.v.). Under these conditions the neuronal population was $>90 \%$ as determined by microtubule-associated protein 2 immunohistochemistry (data not shown). Experiments were performed at 14 d.i.v.

\subsection{PC12 cell culture}

Rat pheochromocytoma PC12 cells were kindly provided by Professor Karen Chapman (University of Edinburgh) and used at passage 8-16. Cells were plated onto collagen-coated tissue culture flasks and cultured in Dulbecco's modified Eagle's medium (DMEM; Lonza, Slough, UK) supplemented with $10 \%$ foetal bovine serum, $5 \%$ horse serum, $2 \mathrm{mM} \mathrm{L-glutamine,} 50 \mathrm{U} / \mathrm{ml}$ penicillin, $50 \square \mathrm{g} / \mathrm{ml}$ streptomycin (all Invitrogen) at $37^{\circ} \mathrm{C}$ in a hum idified $95 \%$ air $/ 5 \% \mathrm{CO}_{2}$ standard cell culture incubator.

\subsection{Plasmid constructs}

All reporter plasmids are based on the pGL3 basic vector system (Promega) containing the luciferase reporter gene. A fragment of the rat $M R \alpha$ promoter ranging from -1440 to +90 (designated +1 transcription start of MR exon $1 \alpha$, Genbank ${ }^{\mathrm{TM}}$ accession number NM 013131) originally in pBL luc 5'-1500 (-1400/+117; gift from Dr M. Castren, University of Kuopio, Finland) was subcloned into the pGL3 basic vector $(M R-P \alpha)$. Promoter fragments of MR $\beta(-280 /+28$; MR$\mathrm{P} \beta)$ and $\mathrm{MR} \gamma(-1719 /+17$; MR-P $\gamma)$ were amplified from rat genomic DNA by PCR using the primers as shown in Table 1. PCR products were obtained using Pfx polymerase (Invitrogen) under the following cycling conditions: $9^{\circ} \mathrm{C}$ for $2 \mathrm{~min}$; $30 \mathrm{cycles}$ of $9^{\circ} \mathrm{C}$ for $15 \mathrm{sec}, 5^{\circ} \mathrm{C}$ for $30 \mathrm{sec}$, and $68^{\circ} \mathrm{C}$ for $30 \mathrm{sec}$; and extension at $68^{\circ} \mathrm{C}$ for $20 \mathrm{~min}$, then purified for blunt-end cloning into the Smal site of the PGL3 basic vector.

Exon-1 specific DNA fragments were amplified following reverse transcription of rat hippocampal total RNA using primers specific for each alternate exon 1 (Table 1). For probe fragments for ribonuclease protection assay (RPA) a common reverse primer complementary to exon 2 was used to amplify each MR variant. PCR products were obtained using Taq polymerase (Promega) under the following conditions: $9^{\circ} \mathrm{C}$ for $8 \mathrm{~min}$; 30 cycles of $95^{\circ} \mathrm{C}$ for $1 \mathrm{~min} ; 5^{\circ} \mathrm{C}$ for 1 $\mathrm{min} ; 7^{\circ} \mathrm{C}$ for $1 \mathrm{~min}$; and final extension at $72^{\circ} \mathrm{C}$ fo $\mathrm{r} 10 \mathrm{~min}$. Purified fragments were then cloned into pGEM-T Easy vector (Promega) and used as templates for the generation of exon-1 specific cRNA probes.

\subsection{Transient transfection assay}

PC12 cells were plated onto collagen type IV-coated 6 well plates and at $50-60 \%$ confluency were transiently transfected with $0.5 \mu \mathrm{g}$ promoter insert-containing pGL3 plasmid and $0.5 \mu \mathrm{g}$ of the $\beta$-galactosidase expression plasmid $\mathrm{pCH} 110$ for normalization of transfection efficiency, using lipofectamine 2000 ${ }^{\mathrm{TM}}$ (Invitrogen). Cells transfected with the promoterless pGL3 vector served as the baseline control. Transfected cells were differentiated $24 \mathrm{hr}$ later by culturing in serum-free DMEM medium containing $50 \mathrm{ng} / \mathrm{ml}$ nerve growth factor (NGF, Millipore, Watford, UK). Differentiated cells displayed neurite extensions and tyrosine hydroxylase immunoreactivity and were exposed to cell stress 3 days after NGF exposure.

\subsection{Cell stress}


Transfected PC12 cells and primary cortical cultures were subjected to hypothermia (HYPO, $3^{\circ} \mathrm{C}$ ), oxygen-glucose deprivation (OGD) or hypother mic OGD $(\mathrm{OGD} / \mathrm{H})$ for 6 hrs then returned to normal incubation conditions for a further $18 \mathrm{hrs}$ before analysis. To induce HYPO, cells were incubated in a standard tissue culture incubator at $33^{\circ} \mathrm{C}$ and then returned to $37^{\circ} \mathrm{C}$ for $18 \mathrm{hrs}$. For the OGD experiments, cells were washed with glucose-free DMEM medium and incubated with preequilibrated oxygen- and glucose-free medium in a custom made temperature $\left(3^{\circ} \mathrm{C}\right)$ and $\mathrm{CO}_{2}$ (5\%)-controlled anaerobic glove box (Coy Laboratories Ltd, Grass Lake, MI, USA) for 6 hrs then allowed to recover under normal conditions of oxygen and glucose for $18 \mathrm{hrs}$ to mimic ischemic reperfusion. For OGD/H experiments, cells were treated as for the OGD experiments except that the temperature in the glove box was set at $33^{\circ} \mathrm{C}$. F or experimental controls, cells were subjected to the same procedures but incubated in glucose-containing media under normoxic and normothermic conditions in a standard cell culture incubator. The duration of OGD incubation was initially determined from time course experiments using lactate dehydrogenase (LDH) release as a measure of cell damage: a $6 \mathrm{hr}$ incubation period which caused approximately 20\% LDH release (data not shown) was taken to be representative of a sub-lethal challenge. The same time-point was used for OGD/H and HYPO alone although in pilot experiments LDH release was lower after 6 hrs presumably due to a protective effect of hypothermia.

To disrupt signal transduction pathways potentially mediating MR promoter activity, the selective MEK1 inhibitor PD98509 $(25 \mu \mathrm{M})$, JNK inhibitor SP600125 $(2 \mu \mathrm{M})$, p38 inhibitor SB203580 $(1-10 \mu \mathrm{M})$ and cAMP-dependent protein kinase A inhibitor KT $5720(1 \mu \mathrm{M}$; all Merck Biosciences, Nottingham, UK) were added to fresh culture medium $2 \mathrm{hr}$ prior to cell stress.

\subsection{Luciferase and $\beta$-galactosidase assays}

After exposure to relevant stimuli, culture medium was removed and cells were washed with PBS then lysed in $300 \mu \mathrm{l}$ cell lysis buffer. Cell lysates were centrifuged and $40 \mu \mathrm{l}$ supernatant was assayed in triplicate for luciferase activity using a microplate luminometer (Berthold, Alrewas, UK) with beetle luciferin (Promega) as the substrate. $\beta$-galactosidase activity was determined to correct for variation in transfection efficiency using the Tropix/Galacto Light kit (Cambridge Bioscience, Cambridge, UK). Luciferase activity was expressed relative to $\beta$-galactosidase activity.

\subsection{Ribonuclease Protection Assay}

Total RNA was isolated from primary cortical cultures by Trizol (Invitrogen) extraction according to the manufacturer's instructions. The concentration and integrity of each RNA preparation was estimated spectrophotometrically and by ethidium bromide staining after agarose gel electrophoresis. Exon 1 specific antisense and sense RNA probes were synthesized from corresponding linearized plasmids (described above) by in vitro transcription (Promega) with $\mathrm{T}_{7}$ or $\mathrm{SP}_{6}$ polymerase as appropriate in the presence of $[\alpha-32 \mathrm{P}]-\mathrm{GTP}(3000 \mathrm{Ci} / \mathrm{mmol}$; GE Healthcare, Amersham, Bucks, UK). The antisense probe of the $\beta$-actin gene served as the internal control and was synthesized in the same manner. RPAs were performed using the HybSpeed ${ }^{\mathrm{TM}}$ RPA kit (Ambion, Warrington, UK) according to the manufacturer's instructions. Total RNA $(20 \mu \mathrm{g})$ was coprecipitated with $5 \times 10^{5} \mathrm{cpm}$ riboprobe, resuspended in hybridization buffer and incubated at $68^{\circ} \mathrm{C}$ for $1 \mathrm{hr}$. Following RNase digestion (RNAse A/T1 1:25 dilution), protected probes were separated on polyacrylamide/urea gels and quantified by Phosphorimage (FujiFilm FLA-2000) analysis in conjunction with AIDA v2.0 software (Raytek, Sheffield, UK). The quantity of protected probe was normalized with reference to simultaneously hybridized $\beta$-actin mRNA expression.

\subsection{Neonatal anoxia}

Anoxia was induced in newborn Wistar rats of both sexes at postnatal day (PND) 2, as previously described (Caputa et al., 2001; Rogalska et al., 2004). Briefly, pups were placed in temperature controlled plethysmographic chambers at either $3^{\circ} \mathrm{C}$ (normal body temperature for PND 2 rats) or $31^{\circ} \mathrm{C}$ (hypothermia). Rectal temperatu re was measured and as soon as the desired body temperature was reached, anoxia was induced by flushing $100 \%$ nitrogen into the chambers. 
Respiratory effort was constantly monitored using the barometric method and animals were maintained under anoxic conditions for $25 \mathrm{~min}$. After anoxia, animals were exposed to atmospheric air at unchanged temperature for 120 min then sacrificed. Brains were dissected and frozen on dry ice. Control rats were placed into the chambers and exposed to atmospheric air over the same period of time (145 $\mathrm{min}$ ) under the respective temperature conditions.

\subsection{In situ hybridization}

Coronal sections $(12 \mu \mathrm{m})$ of fresh frozen brains were processed for in situ hybridization using ${ }^{35}$ S-UTP (GE Healthcare) labelled exon 1 specific RNA probes as described above. Probes were annealed at a temperature of $50^{\circ} \mathrm{C}$ for $16 \mathrm{hrs}$ a nd sections were washed, RNAse digested, dehydrated and exposed to photographic liquid emulsion (LM-1; GE Healthcare). Slides were developed three weeks later with Kodak 19 developer and hybridization signal was assessed by computer assisted quantitative grain counting (MCID Research Imaging, Canada).

\subsection{Statistical analysis}

All analyses were performed by an investigator blinded to experimental condition. Measurements from individual PC12 and primary cortical preparations were performed in triplicate for each experiment. All data are represented as the mean \pm SEM. for the number of experiments indicated. Statistical analyses of experiments were performed by ANOVA followed by post-hoc comparisons using Tukey's multiple test (to compare values against each other) or Bonferoni's comparison test (to compare values against control). Values of $p<0.05$ were considered statistically significant.

\section{Results}

\subsection{Cell stress stimulates differential expression of variant MR mRNA transcripts}

To investigate how injury-induced MR might be regulated we initially used dissociated embryonic cortical neuronal cultures. These cultures express MR at levels approximately half that of hippocampal neuronal cultures but respond to cell stress in a similar manner (Macleod et al., 2003) and therefore provide a suitable model for the purpose of this study.

The effects of HYPO, OGD or OGD/H on the abundance of the three specific MR mRNA variants $M R \alpha, M R \beta$ and $M R \gamma$, were determined by ribonuclease protection assay with specific riboprobes targeted to each variant exon 1 and complementary to the first 180 nucleotides of exon 2 (common to all MR mRNA variants). All three MR mRNA variants were detected in primary cortical culture with MR $\alpha$ and MR $\beta$ present in roughly equal proportion and MR $\gamma$ approximately fourfold less abundant (data not shown). Neither HYPO nor OGD altered the expression of the individual MR mRNA variants (Fig. 1). In contrast, OGD/H led to a significant induction of MR $\beta$ mRNA levels $(p<0.05)$, but not those of MR $\alpha$ or MR $\gamma$.

\subsection{MR promoter activity in response to cell stress}

To examine further the upregulation of MR mRNA following cell stress we prepared luciferase reporter constructs containing the proximal promoter for each MR exon 1 variant and measured transcriptional activity at the promoter level in differentiated $\mathrm{pC} 12$ cells in response to $\mathrm{HYPO}, \mathrm{OGD}$ and $\mathrm{OGD} / \mathrm{H}$. Although differentiated PC12 cells do not express endogenous MR, both $M R \alpha$ and $M R \gamma$ promoters showed significantly greater basal activity compared to pGL3 $(p<0.001)$ whereas MR $\beta$ promoter activity was not significantly different to pGL3 (Fig. 2) suggesting at least some of the signal pathways for MR promoter activity are active. Exposure to cell stress led to differential activation of the MR promoters: both MR $\alpha(p<0.01)$ and MR $\beta(p<0.05)$ promoter activity was increased by OGD/H but not by OGD or HYPO alone. However we found no effect on MR $\gamma$ promoter activity. Cell stress per se did not affect $\beta$-gal activity (data not shown). 


\subsection{ERK signalling pathway mediates cell stress activation of MR promoter}

We previously reported an association between increased MR mRNA and activation of the extracellular signal regulated kinase (ERK) pathway in primary neuronal cultures subjected to cell stress (Macleod et al., 2003). To assess the involvement of this signalling pathway in OGD/H induced $M R \alpha$ and MR $\beta$ promoter activity, we treated transfected differentiated PC12 cells with the selective ERK pathway inhibitor PD98059 prior to exposure to OGD/H. To test if other components of the mitogen activated kinase (MAPK) pathway were involved in promoter activation, we also separately treated cells with the JNK pathway inhibitor SP600125, the p38 MAPK inhibitor SB203580 or the CAMP dependent protein kinase A (PKA) inhibitor KT5720.

$\mathrm{OGD} / \mathrm{H}$-induced MR promoter activation appears to be mediated by specific signalling pathways (Fig. 3): we found no effect of inhibitor on basal MR $\alpha$ activity other than the p38 kinase inhibitor SB203580 which caused an apparent increase in basal MR $\alpha$ activity. However SB203580 did not inhibit $\mathrm{OGD} / \mathrm{H}$ induced $\mathrm{MR} \alpha$ promoter activity implying that $\mathrm{p38}$ kinase is not involved in this activation. Similarly there was no inhibitory effect of KT5720. In contrast, both PD98059 and SP600125 attenuated $\mathrm{OGD} / \mathrm{H}$-induced activation of $\mathrm{MR} \alpha$ promoter activity to levels comparable to that seen under control conditions $(p<0.05)$ suggesting a requirement for ERK1/2 and JNK signalling. Interestingly PD98059 inhibition reduced OGD/H-induced MR $\alpha$ promoter activity to twofold lower than control. We found no effect of inhibitor on $\beta$-gal promoter activity (data not shown).

For the MR $\beta$ promoter there was no effect of inhibitor on basal MR $\beta$ promoter activity; PD98059 significantly attenuated OGD/H-induced MR $\beta$ promoter activity $(p<0.001)$, but SP600125, KT5720 and SB203580 had no effect. This suggests that OGD/H-induced MR $\beta$ induction is mediated by ERK1/2 signalling alone (Fig. 3).

\subsection{Differential regulation of variant MR mRNA transcripts by hypothermia and anoxia in neonatal} rat brain

To investigate whether the changes in the expression profiles of the variant MR mRNA transcripts in vitro were reflected in vivo and therefore of biological importance, we used a well characterized neonatal rat model of anoxia where body temperature can be manipulated (Caputa et al., 2001; Rogalska et al., 2004). We measured changes in the expression of MR variant transcripts and total MR mRNA in the hippocampus because this region has high basal expression of MR and is particularly vulnerable to ischemia.

Firstly, in situ hybridization using a probe complementary to the coding region which does not distinguish between the MR variants showed that total MR mRNA in neonatal hippocampus under control conditions was most highly expressed in the CA3 and DG with lower expression in CA1, CA2 and CA4 (Fig. 4). Results revealed that total MR mRNA was significantly induced by hypothermia $(p<0.05)$ but not by anoxia in all hippocampal regions except CA4 where total mRNA levels were induced in response to anoxia $(p<0.05)$. However there was no synergistic effect of hypothermia and anoxia (n.s.).

To determine which variant MR transcript might be responsible for the upregulation of total MR mRNA, exon-1 specific probes were used to analyse adjacent brain sections. Under control conditions, all three MR mRNA transcripts were detectable in rat hippocampus at PND 2 with the same regional pattern of expression as seen for total MR mRNA (Fig. 4). Of the three variant transcripts, only MR $\beta$ was significantly altered by the experimental procedure: across all regions, the MR $\beta$ transcript was significantly increased under hypothermic compared to normothermic conditions $(p<0.05)$ irrespective of oxygen status.

\section{Discussion}

Here we show, both in vitro and in vivo, that MR transcripts are differentially regulated in response to injury. Under clinically relevant conditions, the MR $\beta$ transcript is specifically upregulated in neurons via the MR $\beta$ promoter, an effect which appears to be mediated through the ERK1/2 pathway and which appears not to involve other MAP kinase pathways. We found no changes in MR $\gamma$ and while $M R \alpha$ promoter activity was enhanced by OGD/H exposure in 
differentiated PC12 cells, this was not associated with elevated transcript levels either in vitro or in vivo. To our knowledge this is the first demonstration of the differential regulation of alternate MR promoters in response to cell stress and implicates the MR $\beta$ promoter as a major regulatory point for MR mRNA expression in response to cell injury.

Variation in expression and differential regulation of the MR transcripts has previously been reported to occur during brain development where both the MR $\beta$ and MR $\gamma$ are expressed during development but decline in adulthood (Vazquez et al., 1998). Cellular responses to brain injury often appear to recapitulate events that occur during development (Chen et al., 2005) and so activation of the MR $\beta$ promoter with increased MR $\beta$ expression is a plausible response to injury. Our data suggests that this occurs only in response to specific cell stressors. Mild to moderate hypothermia is generally held to have modest effects under normal conditions but the combination of hypothermia and ischemia generally leads to a reduction in the extent of ischemic damage (Buslo et al., 1989; Green et al., 1992; Kollmar et al., 2002; van der Worp et al., 2007). While the exact mechanism by which hypothermia exerts this protective effect is not clear, changes in gene expression have been reported (Ohta et al, 2007; Kobayashi et al., 2008). Our present findings support an important role for hypothermia-induced changes in gene expression and also corroborate our previous observations of increased hippocampal total MR mRNA expression in adult rats subjected to hypothermic but not normothermic transient global cerebral ischemia (Macleod et al., 2003) where blockade of MR exacerbated ischemic damage.

Therapeutic cooling is used in the management of hypoxic-ischemic encephalopathy in neonates (Hoehn et al., 2008) but to date the effects in adult ischemic stroke or traumatic brain injury have yet to be established. Importantly there may be age-dependent differences in the response to hypothermia. Indeed, the regulation of MR appears to be different in neonatal rat brain where MR expression is increased, again via the MR $\beta$ transcript, in response to hypothermia but not to anoxia. In contrast to primary cortical culture, there was no significant increase in MR $\beta$ expression with hypothermic anoxia compared with hypothermia alone. The lack of an injury (anoxia) induced increase in MR may be due to the fact that normal body temperature in neonates is $3^{\circ} \mathrm{C}$ and this in itself may be an adaptive respo nse to take advantage of protective responses occurring at this temperature. Indeed we saw little evidence of neuronal damage in normothermic anoxia in contrast to our observations in the adult rat (Macleod et al., 2003) and human brain (Lai et al., 2008) where such changes are clearly seen, and may explain why MR is not additionally induced by anoxic hypothermia. Intriguingly we have also observed MR $\beta$ transcript unregulation in hyperthermic $\left(3^{\circ} \mathrm{C}\right)$ neonatal rat brain (Rogalska et al., 2009) in the absence of any effect on neuronal viability and the most plausible explanation is that MR induction occurs as an endogenous response to thermal stress to protect the brain from subsequent injury. Confirmation of specific MR $\beta$ upregulation in the adult brain needs to be sought but nonetheless, these data lend further support our hypothesis that increased MR expression forms a component of the response to hypo(and hyper-) thermia and that MR $\beta$ is the major driver of this response.

We investigated further the upstream regulation of injury-induced MR $\beta$ promoter activity and found involvement of the ERK member of the MAP kinase signalling pathway. ERK signalling is primarily activated by mitogens such as growth factors, phorbol esters and serum (Rossler et al, 2004; Hetman et al., 1999; Gause et al., 1993; Whitmarsh et al., 1995) but can also be stimulated by various cell stressors (Lewis et al., 1998; Ji et al., 1999). Phosphorylated ERK is found to a greater degree in the penumbra than in the ischemic core (Irving et al., 2000; Ferrer and Planas, 2003) and crucially is present at much higher levels in ischemia resistant regions of the hippocampus (Gu et al., 2001; Zablocka et al., 2003). Hypothermic neuroprotection also coincides with ERK activation (Hicks et al., 2000) and taken together this body of evidence generally supports a protective role for ERK signalling. Furthermore in silico analysis shows that there is a putative binding site for the ERK downstream effector, Elk-1, within the MR $\beta$ promoter. Interestingly, it has been shown that injury enhances Elk-1 phosphorylation (Ferrer et al., 2002). Our present findings suggest that ERK activation favours neuronal survival through enhancing MR expression. Although we previously showed that blockade of ERK inhibited injury-induced total MR mRNA expression in primary neuronal culture, we have yet to confirm that this is due to a reduction in MR $\beta$ transcript expression. Whether Elk-1 plays a role in regulating MR $\beta$ remains to be investigated. 
In summary, we provide evidence for specific transcriptional regulation of the MR gene by different conditions of neuronal stress. Therapeutic hypothermia during ischemia increases MR, primarily via an increase in the transcription of MR $\beta$, which enhances survival in injured neurons. Since hypothermia is difficult to deliver clinically, targeted upregulation of MR $\beta$ in neurons may provide a suitable target for future therapeutic strategies in conditions characterized by cerebral ischemia including stroke and cardiac arrest.

\section{References}

Buslo, R., Dietrich, W.D., Globus, M.Y., Ginsberg, M.D., 1989. Post-ischemic moderate hypothermia inhibits CA1 hippocampal ischemic neuronal injury. Neurosci. Lett. 101, 299-304.

Caputa, M., Rogalska, J., Nowakowska, A., 2001. Effect of temperature on postanoxia, potentially neurotoxic changes of plasma pH and free iron level in newborn rats. Brain Res Bull. 55, 281286.

Chen, J., Leong, S.Y., Schachner, M., 2005. Differential expression of cell fate determinants in neurons and glial cells of adult mouse spinal cord after compression injury. Eur. J. Neurosci. 22, 1895-1906.

de Kloet, E.R., Vreugdenhil, E., Oitzl, M.S., Joels, M., 1998. Brain corticosteroid receptor balance in health and disease. Endocr. Rev. 19, 269-301.

Evans, R.M., Arriza, J.L., 1989. A molecular framework for the actions of glucocorticoid hormones in the nervous system. Neuron 2, 1105-1112.

Ferrer, I., Blanco, M., Carmona, B., Puig, B., Dominguez, I., Vinals, F. 2002. Active, phosphorylation-dependent MAP kinases MAPK/ERK, SAPK/JNK and p38 and specific transcription factor substrates are differentially expressed following systematic administration of kainic acid to the adult rat. Acta Neuropathol. 103, 391-407.

Ferrer, I., Planas, A.M., 2003. Signaling of cell death and cell survival following focal cerebral ischemia, life and death struggle in the penumbra. J. Neuropathol. Exp. Neurol. 62, 329-339.

Gause, K.C., Homma, M.K., Licciardi, K.A., Seger, R., Ahn, N.G., Peterson, M.J., Krebs, E.G., Meier, K.E., 1993. Effect of phorbol ester on mitogen activated protein kinase kinase activity in wild type and phorbol ester resistant EL4 thymoma cells. J. Biol. Chem. 22, 16124-16129.

Green, E.J., Dietrich, W.D., van dijk, F., Busto, R., Markgraf, C.G., McCabe, P.M., Ginsberg, M.D., Scheiderman, N., 1992. Protective effect of brain hypothermia on behaviour and histopathology following global cerebral ischemia in rats. Brain Res. 580,197-204.

Gu, Z., Jiang, Q., Zhang, G. 2001. Extracellular signal-regulated kinase 1/2 activation in hippocampus after cerebral ischemia may not interfere with post-ischemic cell death. Brain Res. 901, 79-84.

Hetman, M., Kanning, K., Cavanaugh, J.E., Xia, Z., 1999. Neuroprotection by brain derived neurotrophic factor is mediated by extracellular signal-regulated kinase and phosphatidylinositol 3-kinase. J. Biol. Chem. 274, 22569-22580.

Hicks, S.D., Parmela, K.T., DeFranco, D.B., Klaun, E., Callaway, C.W., 2000. Hypothermia differentially increases extracellular signal-regulated and stress activated protein kinase/c-Jun terminal kinase activation in the hippocampus during reperfusion after asphyxial cardiac arrest. Neuroscience 98, 677-685.

Irving, E.A., Barone, F.C., Reith, A.D., Hadingham, S.J., Parsons, A.A., 2000. Differential activation of MAPK/ERK and p38/SAPK in neurons and glia following focal cerebral ischemia in the rat. Mol. Brain Res. 77, 65-75.

Ji, R.R., Baba, H., Brenner, G., Woolf, C.J., 1999 Nociceptive-specific activation of ERK in spinal neurons contributes to pain hypersensitivity. Nat. Neurosci. 2, 1114-1119.

Kobayashi, M.S., Asai, S., Ishikawa, K., Nishida, Y., Nagata, T., Takahashi, Y., 2008. Global profiling of influence of intra-ischemic brain temperature on gene expression in rat brain. Brain Res. Rev. 58, 171-191. 
Kollmar, R., Schabitz, W.R., Heiland, S., Georgiadis, D., Schellinger, P.D., Bardutscky, J., Schwab, S., 2002. Neuroprotective effect of delayed moderate hypothermia after focal cerebral ischemia: an MRI study. Stroke 33, 1899-1904.

Kwak, S.P., Patel, P.D., Thompson, R.C., Akil, H., Watson, J., 1993. 5' Heterogeneity of the mineralocorticoid receptor messenger ribonucleic acid: differential expression and regulation of splice variants within the rat hippocampus. Endocrinology 133, 2344-2350.

Lai, M., Seckl, J., Macleod, M., 2005. Overexpression of the mineralocorticoid receptor protects against injury. Mol. Brain Res. 135, 276-279.

Lai, M., Horsburgh, K., Bae, S., Carter, R., Stenvers, D., Fowler, J., Yau, J., Gomez-Sanchez, C., Holmes, M., Kenyon, C., Seckl, J., Macleod, M., 2007. Forebrain mineralocorticoid receptor overexpression enhances memory, reduces anxiety and attenuates neuronal loss in cerebral ischaemia. Eur. J. Neurosci. 25, 1832-1842.

Lai, M., Bae, S.E., Bell, J., Seckl, J.R., Macleod, M.R. Mineralocorticoid receptor mRNA expression is increased in human hippocampus following brief cerebral ischaemia. Neuropath. \& Applied Neurobiol. In press.

Lewis, T.S., Shapiro, P.S., Alun, N.G., 1998. Signal transduction through MAP kinase cascade. Adv. Cancer Res. 74, 49-139.

Macleod, M., Johansson, I., Soderstrom, I., Lai, M., Gido, G., Wieloch, T., Seckl, J., Olsson, T., 2003. Mineralocorticoid receptor expression and increased survival following neuronal injury. Eur. J. Neurosci. 17, 1549-1555.

Ohta, H., Terao, Y., Shintami, Y., Kiyota, Y., 2007. Therapeutic time window of post-ischemic mild hypothermia and the gene expression associated with the neuroprotection in rat focal cerebral ischemia. Neurosci. Res. 57, 424-433.

Reagan, L.P., McEwen, B.S., 1997. Controversies surrounding glucocorticoid mediated cell death in the hippocampus. J. Chem. Neuroanat. 13, 149-167.

Rogalska, J., Caputa, M., Wentowska, K., Nowakowska, A., 2004. Stress-induced behaviour in juvenile rats:effects of neonatal asphyxia, body temperature and chelation of iron. Behav. Brain Res. 154, 321-329.

Rogalska, J., Kang, P., Wotherspoon, W., Macleod, M.R., Lai, M., 2009. Effect of hyperthermia and anoxia on glucocorticoid and mineralocorticoid receptor expression in neonatal rat hippocampus. Neurosci. Lett. 450, 196-200.

Rossler, O.G., Giehl, K.M., Thiel, G., 2004. Neuroprotection of immortalized hippocampal neurons by brain-derived neurotrophic factor and Raf-1 protein kinase: role of extra-cellular signal regulated protein kinase and phosphatidylinositol 3-kinase. J. Neurochem. 88, 1240-1252.

Sapolsky, R.M., 2000. Glucocorticoids and hippocampal atrophy in neuropsychiatric disorders. Arch. Gen. Psychiatry 57, 925-930.

Van der Worp, H.B., Sena, E.S., Donnan, E.S., Howells, D.W., Macleod, M.R., 2007. Hypothermia in animal models of acute ischemic stroke: a systematic review and meta-analysis. Brain 130, 3063-3074.

Vazquez, D.M., Lopez, J.F., Morano, M.I., Kwak, S.P., Watson, S.J., Akil, H., 1998. Alpha, beta, gamma mineralocorticoid receptor messenger ribonucleic acid splice variants: differential expression and rapid regulation in the developing hippocampus. Endocrinology 139, 3165-3177.

Whitmarsh, A.J., Shore, P., Sharrocks, A.D., Davis, R.J., 1995. Intergration of MAP kinase signal transduction pathways at the serum response element. Science 269, 403-407.

Woolley, C.S., Gould, E., Sakai, R.R., Spencer, R.L., McEwen, B.S., 1991. Effects of aldosterone or RU28362 treatment on adrenalectomy-induced cell death in the dentate gyrus of the adult rat. Brain Res. 554, 312-315.

Zablocka, B., Dluzniewska, J., Zajac, H., Domanska-Janik, K., 2003. Opposite reaction of ERK and JNK in ischemia vulnerable and resistant regions of hippocampus: involvement of mitochondria. Mol. Brain Res. 110, 245-252.

Zennaro, M.C., Le Menuet, D., Lombes, M., 1996. Characterization of the human mineralocorticoid receptor gene 5'-regulation region: evidence for the differential hormonal regulation of two alternative promoters via non-classical mechanisms. Mol. Endocrinol. 10, 1549-1560. 


\section{Acknowledgements}

We thank Ms Jessie Hong for excellent technical assistance. This work was supported by the Cunningham Trust and Research into Ageing. ML is a holder of a Research into Ageing Personal Fellowship. MB was a recipient of a British Neuroendocrinology Society Undergraduate Summer Vacation studentship. 


\section{Figure Legends}

Fig. 1. Effect of cell stress on variant MR mRNA expression in rat primary cortical culture. (A) Schematic representation of the rat MR gene and its mRNA transcripts. The MR gene consists of 11 exons including three untranslated first exons, $1 \alpha, 1 \beta$ and $1 \gamma$ (hatched boxes) and 8 translated exons (2-9; white boxes. Each variant MR transcript comprises an untranslated exon spliced to exon 2. The black lines represent the location of each exon 1specific probe. Relative abundance of each variant MR mRNA following (B) hypothermia (HYPO), (C) oxygen-glucose deprivation (OGD) or (D) a combination of OGD and hypothermia $(\mathrm{OGD} / \mathrm{H})$. Results (black bars) are expressed as percent change of untreated controls (white bars). Data represent mean \pm SEM of six independent experiments, with three replicates per experiment. ${ }^{*} \mathrm{P}<0.05 \mathrm{OGD} / \mathrm{H}$ vs non-treated control.

Fig. 2. Effect of cell stress on variant MR promoter activity in differentiated rat PC12 cells. (A) Schematic representation of the MR promoter constructs used in the luciferase reporter assays (B) Relative luciferase activity under basal conditions for each MR variant promoter relative to pGL3. Relative luciferase activity was calculated for cells exposed to (C) HYPO, (D) OGD or (E) OGD/H (black bars) and expressed as a percent change of untreated controls (white bars). Data represent mean \pm SEM of six independent experiments, with three replicates per experiment. ${ }^{*} \mathrm{P}<0.05,{ }^{* *} \mathrm{P}<0.01$ vs $\mathrm{PGL} 3$ or untreated control.

Fig. 3. Comparison of $\mathrm{OGD} / \mathrm{H}$-induced $\mathrm{MR} \alpha$ promoter activity in the presence of MAP kinase pathway inhibitors in differentiated rat PC12 cells. The effect of each inhibitor on (A) $\mathrm{MR} \alpha$ and (B) MR $\beta$ promoter activity expressed as relative luciferase activity either in the presence (black bars) or absence (white bars) of OGD/H. Data represent mean \pm SEM of seven independent experiments, with three replicates per experiment. For $M R \alpha$ promoter: ${ }^{*} \mathrm{P}<0.05$ vs $\mathrm{OGD} / \mathrm{H}$ control; $\# \mathrm{P}<0.05$ vs stressed vehicle control. For MR $\beta$ promoter: ${ }^{*} \mathrm{P}<0.001$ vs $\mathrm{OGD} / \mathrm{H}$ control; $\# \mathrm{P}<0.001$ vs stressed vehicle control

Fig. 4. Effect of hypothermic anoxia on variant MR mRNA expression in neonatal rat hippocampus. Quantitative analysis of (A) MR $\alpha$, (B) MR , (C) MR $\gamma$ and (D) total MR transcript abundance by grain counting under: normothermic/normoxic (white bars); normothermic/anoxic (hatched bars); hypothermic normoxic (black bars) and hypothermic anoxic (shaded bars) conditions. Data represent the mean \pm SEM with six animals per group. ${ }^{\star} \mathrm{P}<0.05,{ }^{* *} \mathrm{P}<0.01,{ }^{* * *} \mathrm{P}<0.001$. Representative autoradiographic images showing distribution of $M R \square(E, F)$; MR $(G, H)$; MR $(\mathrm{I}, J)$ and total MR mRNA (K, L) under normothermic/normoxic $(E, G, I, K)$ or hypothermic/normoxic conditions $(F, H, J, L)$. 


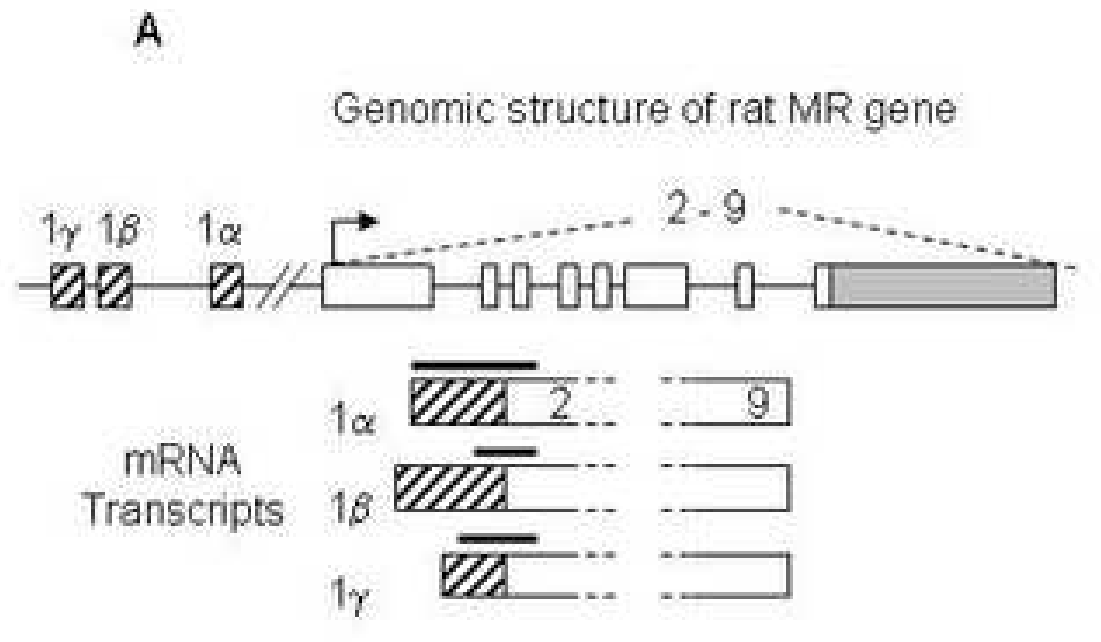

C

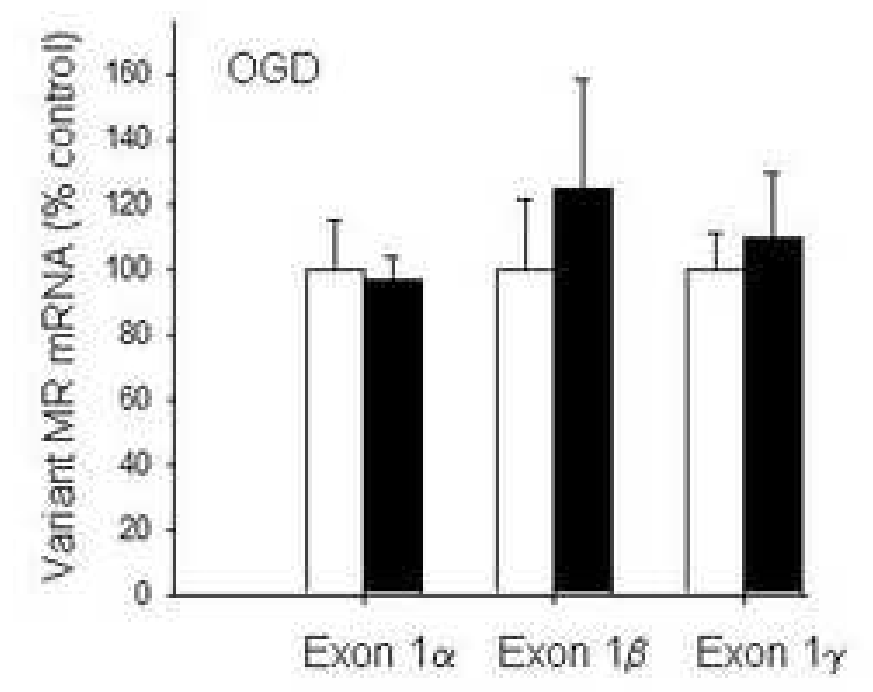

B

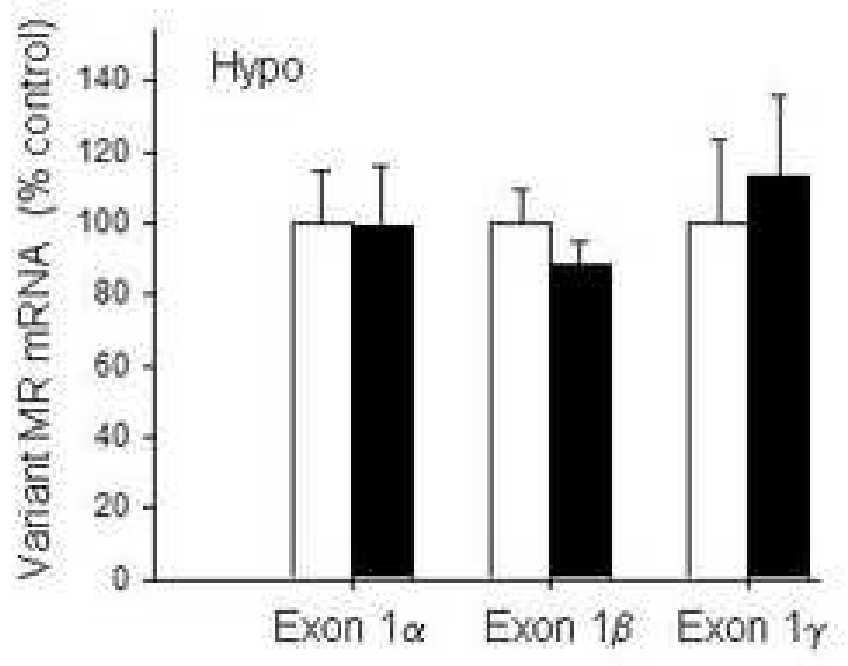

D

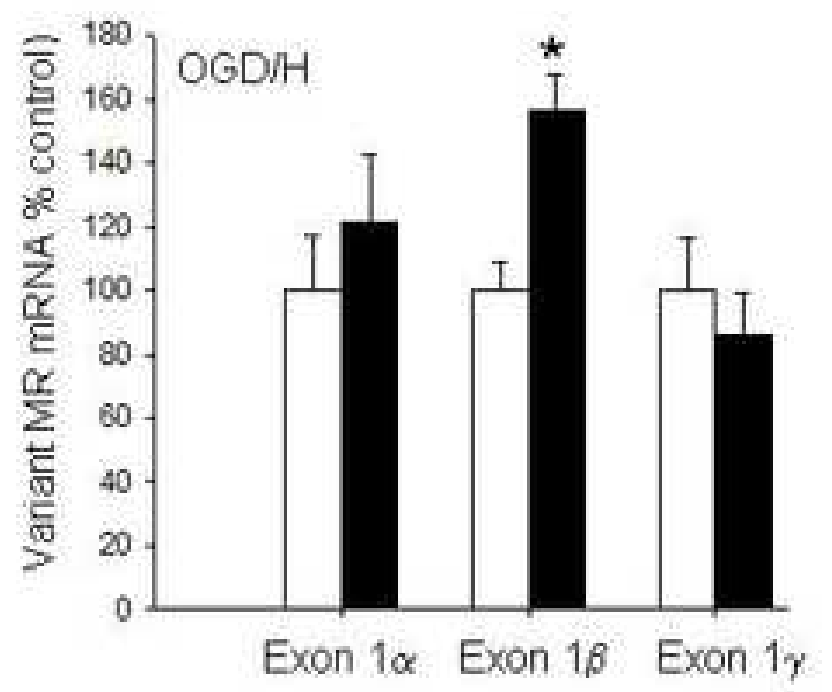


A

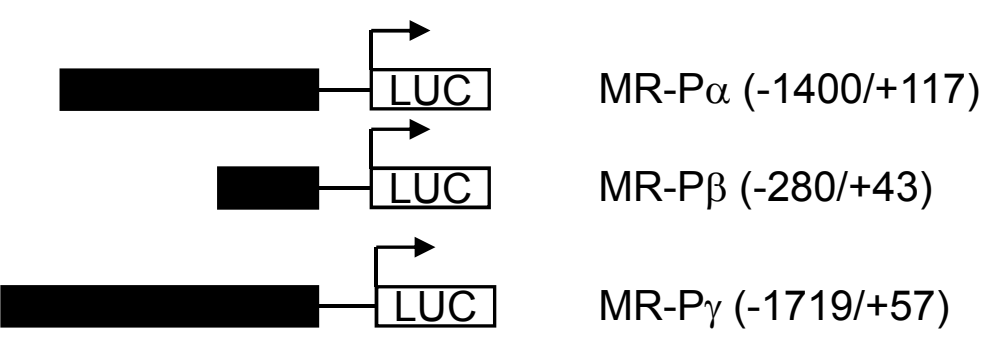

B

C
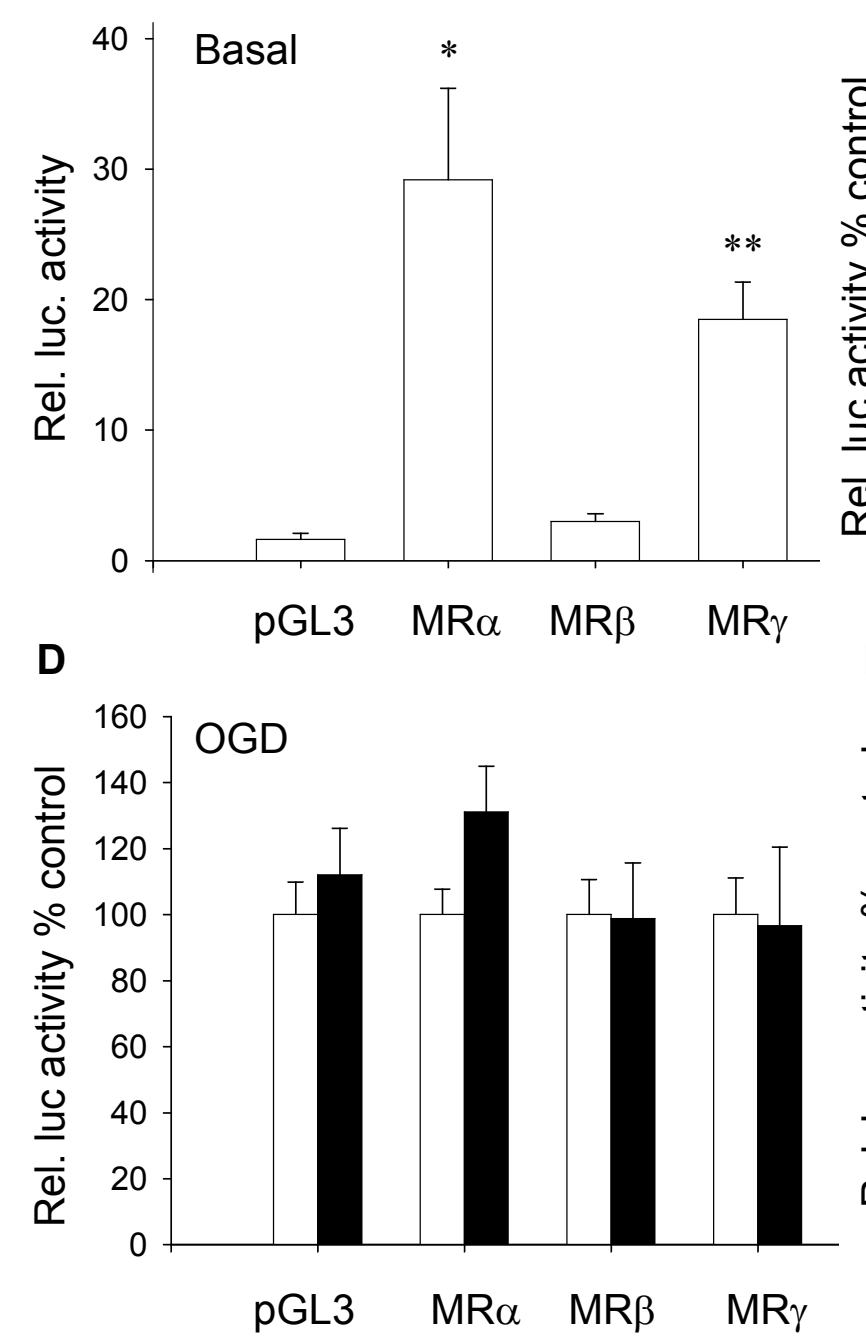

E
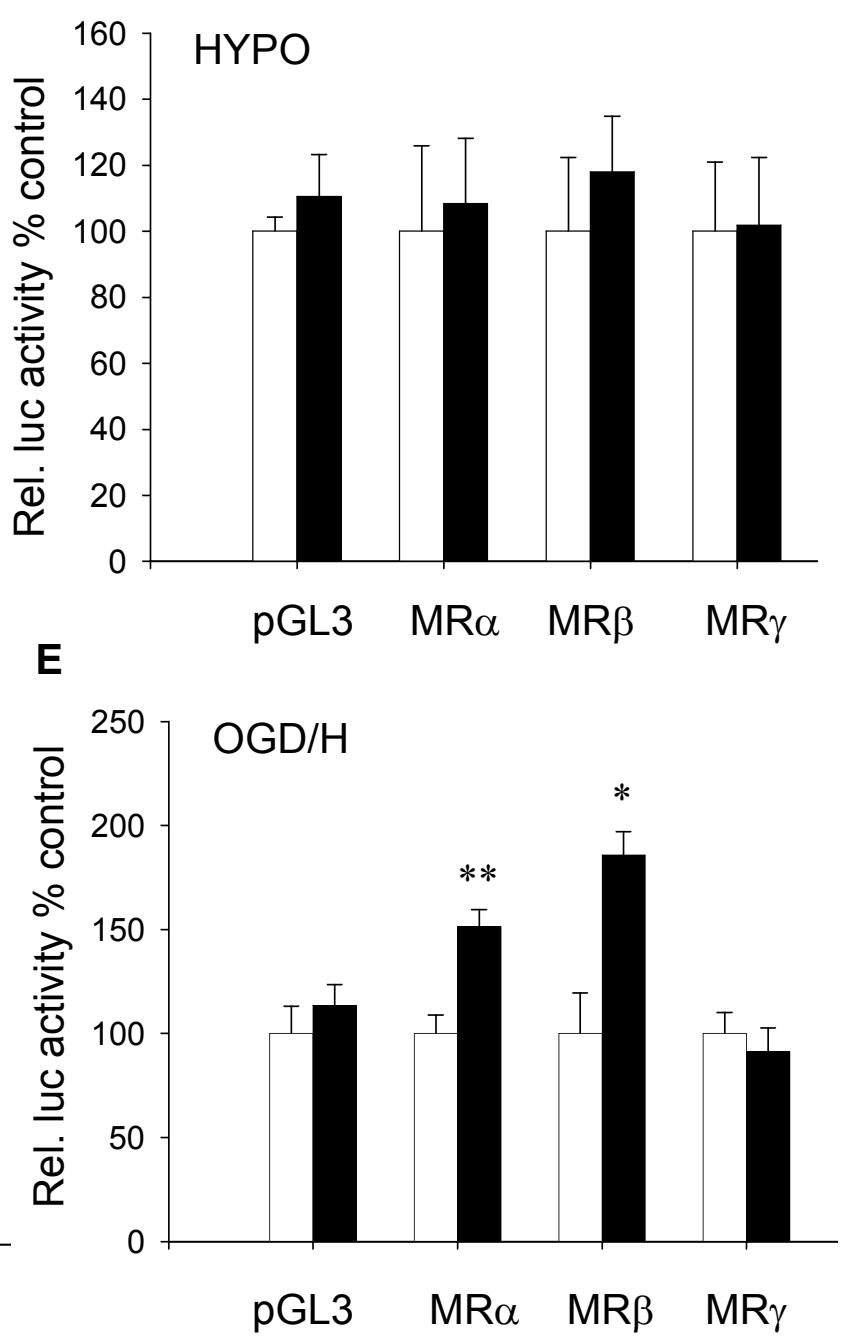
A
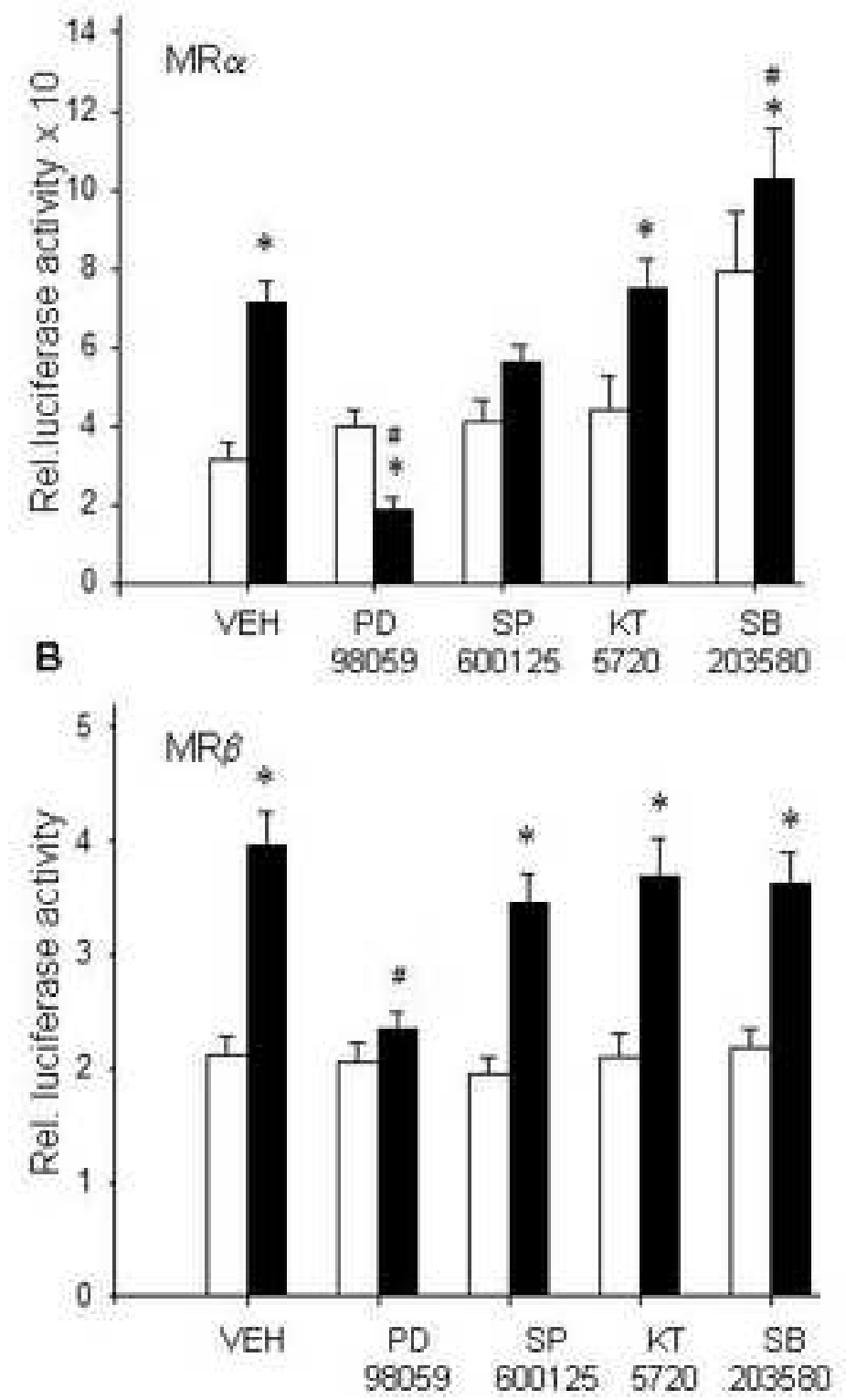

rage 15 or $1 /$ 


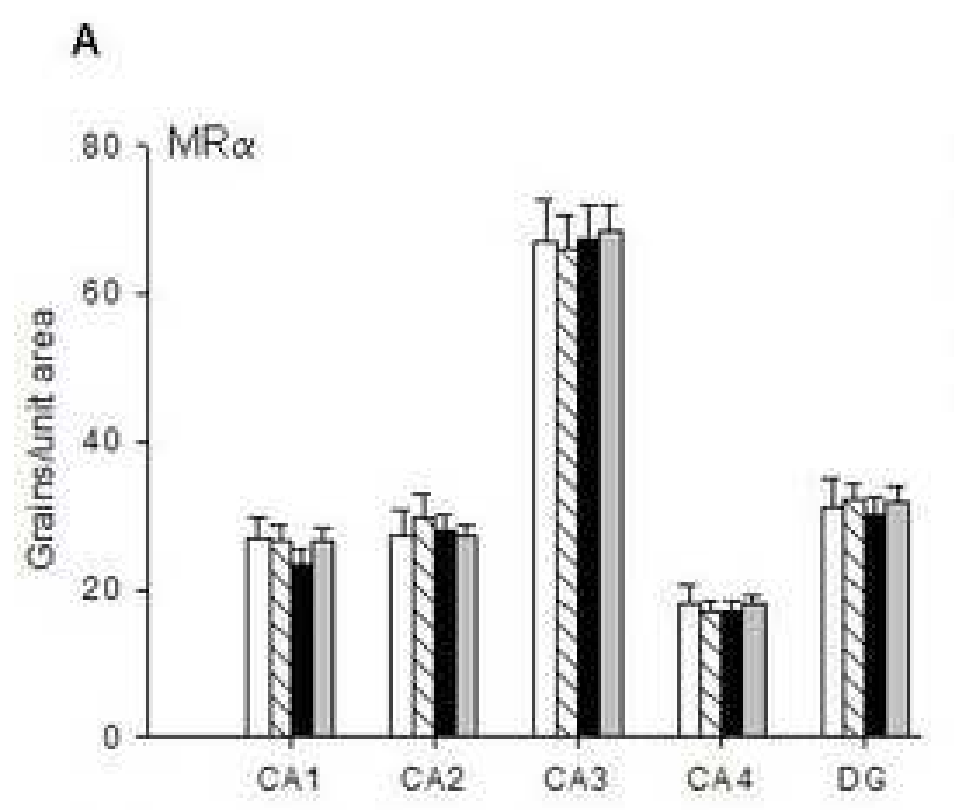

B

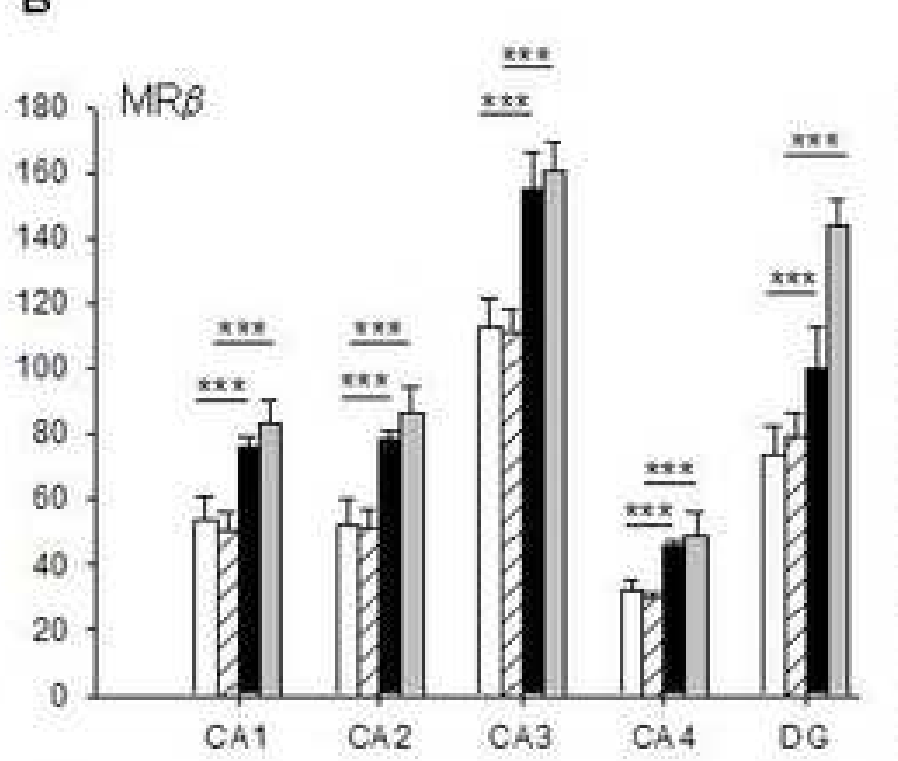

D

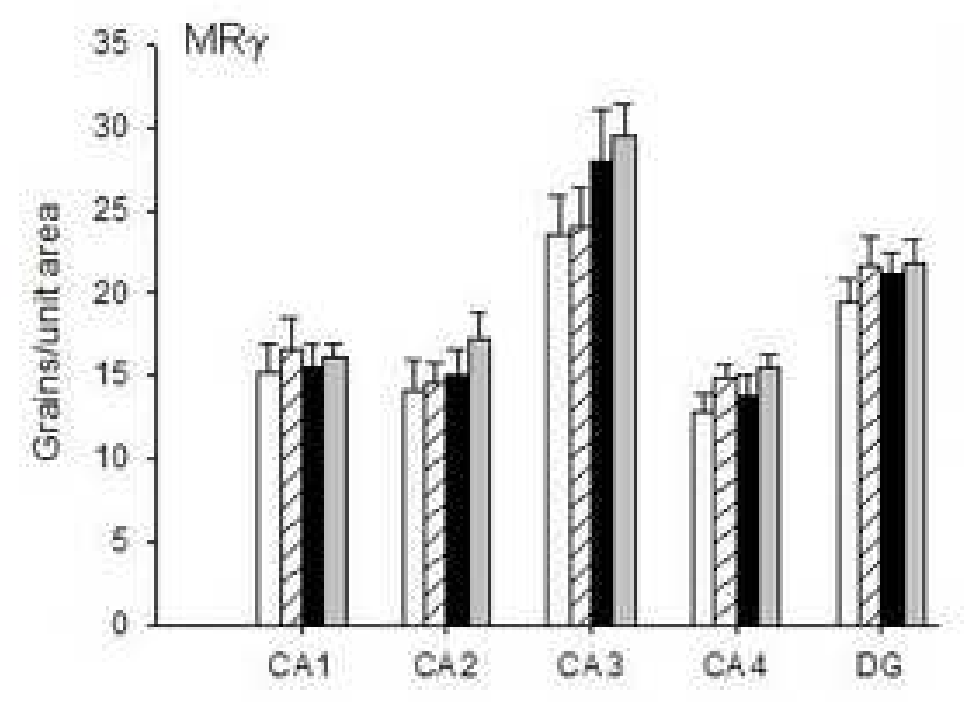

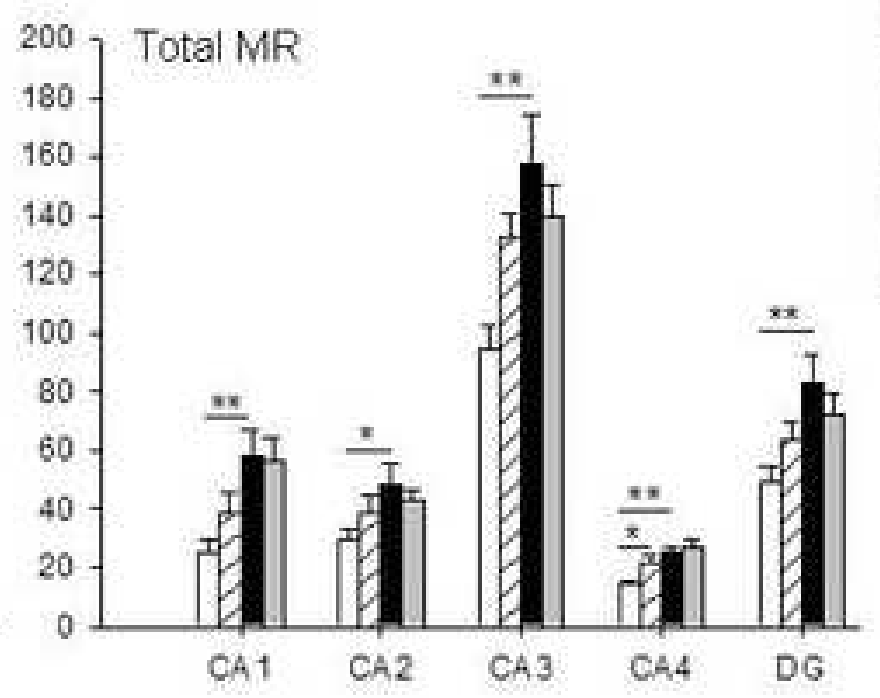
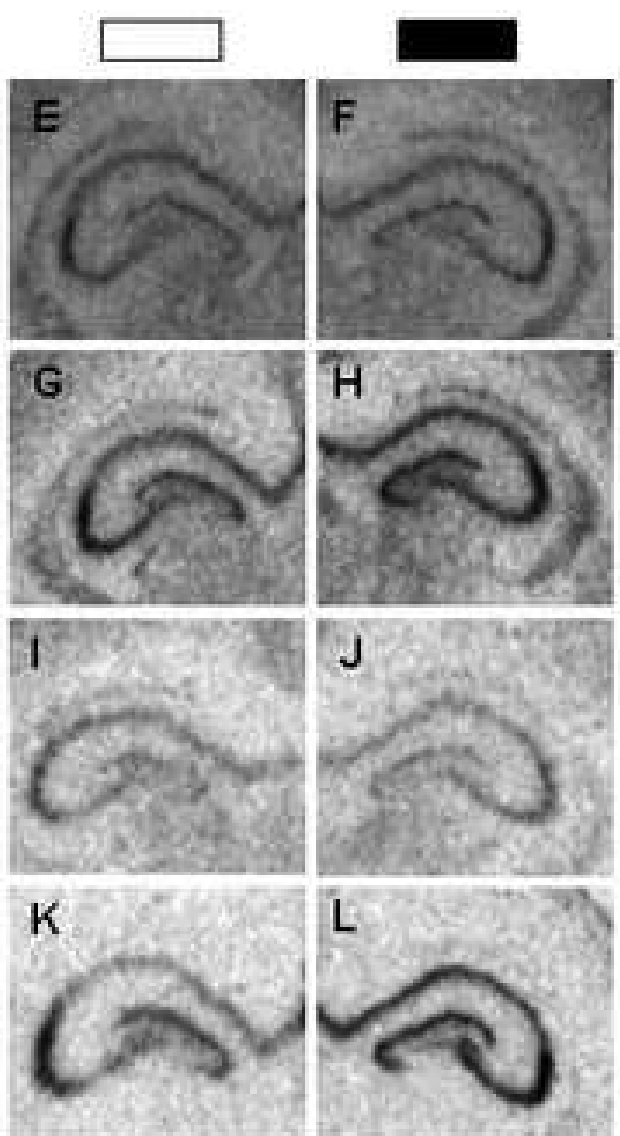

$\square$ Normothermia/normoxia

[I] Normothermia/anoxia

- Hypothermia/normoxia

$\square$ Hypothermia/anoxia 
Table 1. Primer sequences used for PCR amplification of specific DNA sequences

\begin{tabular}{|l|c|c|}
\hline & Forward Primer & Reverse Primer \\
\hline MR-P $\beta$ & 5'TGCACTGGAGTTCCGTTTCC & 5'CGGCGATAGAGAGTGGTTAG \\
\hline MR-P $\gamma$ & 5'ACCTTGAGCCCTGTGTTTGG & 5'GAAGACCAAGAGCGGACTAG \\
\hline$M R \alpha$ (RPA) & 5'AGGAAGAGAGCCAACTTCAGGCTG & 5'GTACTGTTGTTCGGAATAGCACCG \\
\hline$M R \beta$ & 5'AGCCTCCCTAACATGTCCTAG & 5'GTACTGTTGTTCGGAATAGCACCG \\
\hline$M R \gamma$ & 5'TCCTAGTCCGCTCTTGGTCTTC & 5'GTACTGTTGTTCGGAATAGCACCG \\
\hline$M R \alpha$ (in situ) & 5'CGGGAGAAGAGAGCCAACTT & 5'GTCGTCCTCTCGCCGTCTAC \\
\hline$M R \beta$ & 5'GGGTCTTACCGCTCGACTG & 5'AGTCGCTGCACTCACCTTTT \\
\hline$M R \gamma$ & 5'TTCCCTCCTAGTCCGCTCTT & 5'ACGCACCCTGTATGCTTCTC \\
\hline
\end{tabular}

